\title{
Network Effects and Social Inequality
}

\section{Citation}

DiMaggio, Paul, and Filiz Garip. 2012. Network effects and social inequality. Annual Review of Sociology 38: 93-118.

\section{Published Version}

doi:10.1146/annurev.soc.012809.102545

\section{Permanent link}

http://nrs.harvard.edu/urn-3:HUL.InstRepos:10886837

\section{Terms of Use}

This article was downloaded from Harvard University's DASH repository, and is made available under the terms and conditions applicable to Open Access Policy Articles, as set forth at http:// nrs.harvard.edu/urn-3:HUL.InstRepos:dash.current.terms-of-use\#OAP

\section{Share Your Story}

The Harvard community has made this article openly available.

Please share how this access benefits you. Submit a story.

\section{Accessibility}




\title{
Network Effects and Social Inequality
}

\author{
Paul DiMaggio \\ Princeton University \\ Filiz Garip \\ Princeton, NJ 08544 USA \\ dimaggio@princeton.edu \\ Harvard University \\ Cambridge MA 02138 USA \\ fgarip@wjh.harvard.edu
}

December, 2011

[Published in Annual Reviews of Sociology 38, 2012]

Keywords: inequality; network effects; cumulative advantage; threshold models; homophily; externalities; diffusion; spillovers.

Running head: Network effects and inequality

Corresponding author:

Paul DiMaggio

130 Mercer Street

Princeton NJ 08540

6092032109 (cell)

dimaggio@princeton.edu

6092582180 (public fax - must include cover sheet with recipient's name)

Paper prepared for the Annual Review of Sociology. We are grateful to Damon Centola and Gabriel Rossman for helpful feedback on an earlier draft of this paper, to Daniel Nagin for several valuable conversations, and for scholars and staff at the Russell Sage Foundation for invaluable feedback on an oral presentation of these ideas, including helpful written feedback from Delia Baldassarri, Naomi Gerstel, Eric Hilt, Rucker Johnson, Jennifer Lee, Betsy Paluck, and Wendy Rahn. Fellowship support from the Russell Sage Foundation and sabbatical leave from Princeton University are gratefully acknowledged. All deficiencies are authorial. 


\section{Abstract}

Students of social inequality have noted the presence of mechanisms militating toward cumulative advantage and increasing inequality. Social scientists have established that individuals' choices are influenced by those of their network peers in many social domains. We suggest that the ubiquity of network effects and tendencies towards cumulative advantage are related. Inequality is exacerbated when effects of individual differences are multiplied by social networks: when persons must decide whether to adopt beneficial practices; network externalities, social learning, or normative pressure influence adoption decisions; and networks are homophilous with respect to individual characteristics that predict such decisions. We review evidence from literatures on network effects on technology, labor markets, education, demography, and health; identify several mechanisms through which networks may generate higher levels of inequality than one would expect based on differences in initial endowments alone; consider cases where network effects may ameliorate inequality; and describe research priorities. 
Article table of contents with first and second level headings

INTRODUCTION

HOW NETWORKS INFLUENCE CHOICE

RESEARCH BEARING ON NETWORK EFFECTS ON SOCIAL INEQUALITY

Evidence for network effects

Network and peer interaction effects

Direct models of and evidence on network effects on intergroup inequality

FOR WHAT PRACTICES DO NETWORKS AGGRAVATE INEQUALITY MOST?

Simple vs. complex contagion

What makes a contagion complex?

A TAXONOMY OF NETWORK EFFECTS

Pure network externalities

Social learning

Normative influence

CAN NETWORK EFFECTS REDUCE INEQUALITY?

Inverted advantage

Limited homophily

PRIORITIES FOR RESEARCH ON NETWORK EFFECTS ON INEQUALITY 


\section{INTRODUCTION}

"Them that's got shall get; them that's not shall lose;

So the Bible says, and it still is news." 1

"I get by with a little help from my friends."2

Students of inequality have long noted the tendency for small initial advantages and disadvantages to develop into greater differences, and for small intergroup differences to become greater (Merton 1968; Jencks \& Mayer 1990; DiPrete \& Eirich 2006). Students of social networks have long noted the capacity of networks to provide access to valuable resources. This chapter suggests that these two observations are related, in that inequality is aggravated when network effects compound in individual-level advantages in the adoption of behaviors that help people get ahead.

This mechanism may operate under the following conditions (which are necessary but, as we shall see below, not sufficient):

\section{A behavior (pursuing a college degree) or transition (migration) or practice} (using a productivity-enhancing technology) is likely, if adopted or undertaken, to improve adopters' current or future well-being. ${ }^{3}$

2. The probability of adoption is a function both of individual endowments and of the extent to which one's friends and associates have already adopted the practice.

\footnotetext{
1 Billie Holiday and Arthur Hertzog, Jr., "God Bless the Child" (1939).

2 Paul McCartney and John Lennon, "With a Little Help from My Friends" (1967).

${ }^{3}$ For simplicity's sake, we use "practice" below to refer generally to practices, behaviors, and transitions. Because of our interest in inequality, we focus primarily on how networks encourage the adoption of practices that are likely to contribute directly or indirectly to social mobility, lifetime income, health, or other generally desired outcomes. We also consider the role of networks in discouraging the adoption of risky behaviors (e.g., substance abuse or delinquency) that are negative predictors of long-term welfare.
} 
3. Networks are homophilous with respect to individual characteristics associated with adoption, so that likely adopters tend to associate with other likely adopters and likely non-adopters with other probable non-adopters.

Under these conditions, advantages individuals obtain from initial endowments (e.g., financial or cultural resources) may be compounded by network influences, exacerbating intergroup inequality in the adoption of rewarding practices relative to what we would expect based on individual differences alone. ${ }^{4}$

We find it useful to view such effects as resulting from diffusion processes shaped by networks and initial endowments (Rogers 2003). Inequality is exacerbated when an innovation diffuses more broadly within an advantaged than within a disadvantaged group and has positive effects on subsequent welfare. We are concerned both with classic cases of new-product diffusion, e.g. the adoption of new information technologies, and with cases in which diffusion provides a conceptual lens for understanding choices (e.g., about schooling, health behaviors, marriage) that each cohort faces anew.

Although relatively little about networks' impact on population-level inequality, research on network effects, network externalities, homophily, and diffusion processes together establish its plausibility and provides insights for modeling and empirical research. In the next section, we highlight three main classes of network effects - local network externalities, social learning, and normative influence -- any of which, under the right conditions, can exacerbate intergroup inequality. Next, drawing on sociological and economic literatures on network effects on technology adoption, labor markets, migration, demo-

${ }^{4}$ The mechanisms described in this paper generate inequality with respect to the rate and level of adoption of particular beneficial practices. Although we use the shorthand "inequality" for the sake of brevity, our focus is on inequality in rates of adoption of behaviors likely to lead to desirable outcomes, not on those outcomes themselves, which are beyond the scope of this review. 
graphic transitions, education, health, social identity, and the avoidance of risky behaviors, we review evidence on network effects, theoretical arguments and formal models, and a few studies focusing directly on the relationship between networks and changes in intergroup inequality in the adoption of advantageous practices. We conclude that homophily is ubiquitous, that network effects on the adoption of beneficial practices reinforce individual-level differences both directly and, at times, through positive statistical interactions between networks and individual advantages, and that some direct evidence supports the view that network effects exacerbate intergroup difference. Next, we describe the scope conditions under which we would anticipate such effects; and present a taxonomy of mechanisms by which networks influence behavior, with attention to variations in functional form. We conclude by asking whether network effects might, under some conditions, reduce intergroup inequality and by presenting a research agenda.

\section{HOW NETWORKS INFLUENCE CHOICE}

Network effects occur when the probability that an actor will adopt a practice is an increasing function of the number or proportion of persons in the actor's social network who already have adopted that practice. Such effects work through increases in the utility of a practice to an actor, whether achieved through direct impact on payoff, risk-adjusted return, or social sanctions. At the most abstract level, different kinds of network effects can be modeled and understood using a common framework. For any given practice, ego (i.e. the actor at risk to adopt a practice) has a reservation price (the combination of time, money and effort ego will expend towards adoption). Reservation price is ordinarily associated with financial resources (more wealth, fewer tradeoffs) as well as with advantages such as education that may enable one to understand a practice's potential benefits or to 
employ it more productively. Where network effects operate, ego's reservation price, and therefore the likelihood that ego will adopt a practice, increases beyond that predicted by individual endowments alone as the number of prior adopters in ego's network increases. We distill from the literature three classes of network effects. In this section, we introduce them and provide some examples in order to clarify terminology. We discuss the modeling implications (associating each mechanism with distinctive functional forms expressing the relationship between network characteristics and adoption probabilities) at greater length in a subsequent section. These three principle mechanisms include: (1) local network externalities; (2) social learning and peer assistance; (3) normative influence. ${ }^{5}$ Network externalities. Network externalities operate when the value of a practice depends on the number of prior adopters (Shy 2001). Network externalities began to receive extensive attention in economics in the 1980s, primarily among industrial-organization scholars interested in how particular firms or technologies lock in a dominant position in their markets (Arthur 1989). Katz and Shapiro's classic paper (1985) apprehended the importance of externalities for individual choice, positing both direct effects (the larger the

\footnotetext{
5 The absence of a generally accepted vocabulary for describing distinctive kinds of network effects is a source of considerable confusion (Liebowitz \& Margolis 1994). Some authors define "social learning" as a type of "network externality" because prior adoption of a practice by one's peers enhances the likely utility to oneself (Sacerdote 2011). Others distinguish between "social learning" and "externalities" more narrowly defined (Hensvik, Asphjell, \& Nilsson 2011). Some view social learning as a type of "social influence" (Liu, King, \& Bearman 2010), whereas others distinguish sharply between the two (Kohler, Behrman \& Watkins 2000). Because, as we argue below, the functional form of relationships between network measures and reservation price is likely to be different for social learning than for either pure externalities (i.e., those in which advantages flow directly from the size of the network) or normative influence, we find it useful to treat social learning effects as a distinct class of mechanisms. An influential typology (Young 2009) includes normative influence ("social influence"), but restricts it to a "conformity motive"; reserves "social learning" for information gathered from observation of outcomes for prior adopters, but does not include pure externalities, instead promulgating a third category, contagion, that refers to effortless transmission of social behavior - actually, a pseudo-category based on analogy (to biological epidemics) without specifying a social mechanism through which transmission occurs. Our tripartite distinction is most similar to that in Rossman, Chiu \& Mol (2008: 206-207) who distinguish among externalities, information-cascade (one type of what we refer to as "social learning"), and contagion models (normative influence in our typology).
} 
network, the greater its value to each user) and indirect effects (dominant technologies attract more complementary products and produce economies in learning and servicing). Telephone systems initially were viewed as natural monopolies in part because of network externalities, as the first to build a large subscriber base would draw its rivals' customers, who would wish to communicate with as many people as possible (Fischer 1992). ${ }^{6}$ Information and communication technologies (ICTs), of which much of the value comes from access to one's network, constitute the classic example of network externalities (Varian \& Farrell 2004). The Internet provides many examples: social networking sites like Facebook; auction sites like eBay; and software like Adobe Acrobat, which dominated the market for document-preparation software by giving Acrobat Reader away for free, thus expanding the number of people an Acrobat user could reach. Although informationtechnology adoption provides the most striking examples, the value of a choice increases with the size of relevant networks in other domains as well. DeSwaan (2001) argues that network externalities are central to the emergence of regionally dominant languages. And demographers have noted effects on demographic phenomena such as marriage (Drewianka 2003). As members of one's social network and age cohort marry, the stock of potential mates declines (reducing opportunity cost) and friends become less available as leisure companions or confidants (as they spend more time with married peers). Similarly, di-

${ }^{6}$ Whereas economists originally viewed network externalities from the perspective of the firm or the economic system, sociologists and, increasingly, economists now view network effects from the perspective of the potential adopter. Whereas classic work in economics defined "network" either technologically (to refer, e.g., to a railroad, telephone system or electrical grid) or very generally (to refer to all users of a product, whether or not they are socially connected), sociologists (and, increasingly, economists) focus on social networks comprising specific persons linked by some concrete relation. For present purposes, we refer to externalities deriving from one's own contacts' adoption of a practice or technology as "local" (because the networks are specific to ego) and refer to externalities resulting from the sheer number of prior adopters as "global." In earlier work (DiMaggio \& Cohen 2005, DiMaggio \& Garip 2011) we referred to "global" as "general" and "local" as "identity-specific." From here on, we focus exclusively on local externalities, and use "externalities" and "local externalities" interchangeably. Because global externalities benefit any potential adopter, they do not exacerbate intergroup inequality (DiMaggio \& Garip 2011) and are therefore not of interest here. 
vorce may be more attractive as a function of the number of persons in one's social network already divorced, and therefore sexually and socially available (Aberg 2009).

Social learning. Social learning effects operate when network peers provide information that increases the utility of a new practice or reduces its cost or risk. (The passage of information through networks often does all three simultaneously.) Network members may provide information that enables one to get more out of a new technology, for example, discovering additional productive uses for an iPad; or to exploit learning opportunities more fully, as when students form study groups to induce greater work effort.

Social learning also influences behavior through effects on cost and, especially, risk. Cost effects may be simple but decisive, as when a friend tells you that a microwave oven is on sale at a cost below your reservation price. Or network-borne information may lead one to raise one's reservation price due to a reduction in perceived risk). For example, if network peers have already migrated to a nearby city to look for work, they can help one find cheaper lodging and avoid exploitative working conditions (Garip 2008). If one is uncertain about whether to use a new contraceptive device, speaking with friends who have already used it may reduce uncertainty (Kohler, Behrman, \& Watkins 2001).

Normative influence. Normative influence does not affect the intrinsic value or cost of a practice, but operates through social side payments, rewards bestowed on adopters and sanctions exacted on non-adopters by their peers. Influence may operate through positive or negative sanctions: one's inclination to recycle, for example, may be reinforced by the positive response of environmentalist friends; or one's valuation of marriage may increase if one learns that one's romantic life has become a topic of unsympathetic gossip among one's married acquaintances. Normative influence does not just encourage the ad- 
option of beneficial practices. It is also important in inducing actors to refrain from adopting potentially harmful practices, and a large literature addresses network effects on substance abuse and delinquent behavior among youth (Case \& Katz 1991).

\section{RESEARCH BEARING ON NETWORK EFFECTS ON INTERGROUP INEQUALITY}

Scholars who have reviewed the literatures on network effects in particular fields have often concluded that such effects cumulate to higher levels of social inequality. In a review of research on health, Pampel, Krueger \& Denney (2010) state "given that high-SES persons adopt healthy behaviors and associate with other high-SES persons, their networks of social support, influence and engagement promote health and widen disparities." Similarly, Freese \& Lutfey (2011) suggest that network effects may contribute to the greater capacity of high-income people to exploit advances in medical science, causing such advances to widen rather than reduce inequality in health outcomes. Gamoran (2011:112) concludes from a review of the literature on school tracking (a form of induced homophily) that "tracking tends to have no effect on overall academic performance or productivity, but it tends to widen the dispersion of achievement, that is, it increases inequality..." Sociologists are not alone in these intuitions: In a review of work in economics on social interactions, Durlauf \& Ioannides (2010:459) assert that "endogenous social interactions help amplify differences in the average group behavior."

In this section, we consider several kinds of evidence that bears on these propositions. For network effects to exacerbate intergroup inequality in adoption of some practice, three things must be true.

First, at the individual level, the probability of adopting a beneficial practice should be a positive function of the financial or cultural resources at a person's command. In general, 
financial resources increase a person's ability to pay, thus raising his or her reservation price. Cultural resources (ordinarily measured as years of formal education) may influence adoption by increasing awareness of new practices (especially of innovations), increasing comprehension of complex innovations, or enabling people to exploit the practices more fully. The positive correlation of socioeconomic status with most behaviors, resources, and practices that improve people's life chances is perhaps the most robust and generalizable finding in sociology, so this point need not detain us further.

Second, actors' social networks must consist of persons similar to themselves with respect to characteristics that predict adoption of the new practice. Homophily - the tendency of persons to form networks with others to whom they are socioeconomically and demographically similar - has been observed to be ubiquitous across a wide range of contexts. Homophily is characteristic of adult friendship networks (O'Malley \& Christakis 2009; Rivera, Soderstrom \& Uzzi 2010) and the friendship networks of children (Kandel 1978). Socioeconomic and racial homophily have also been observed in marital choice (Rosenfeld 2008; Schwartz \& Mare. 2005). Homophily can result from structural factors or from choice (McPherson, Smith-Lovin \& Cook 2001), but either may generate pressures for greater inequality given the presence of network effects. For example, Blossfeld (2009) suggests that educational homogamy has risen because colleges produce educationally homogeneous networks at just the time mate selection becomes salient, whereas young people who move from secondary school to the workforce encounter more diverse networks, leading to less homogamous matches. Because college graduates also earn more, this pattern tends to exacerbate income inequality (Schwartz 2010). 


\section{Evidence for network effects}

For social networks to produce surplus inequality - i.e., inequality greater than that which individual differences would produce in the absence of network effects -- a final necessary (but not sufficient) condition is that adoption of beneficial practices must be positively associated with prior adoption by one's network peers. Space does not permit us to review extensive literatures on network effects in many fields, nor is it necessary to do so given the availability of useful review essays (see Boyd 1989 on migration; Calvó-Armengol, Patacchini \& Zenou 2009, Sacerdote 2011, and Epple \& Romano 2011 on education; Durlauf \& Ioannides 2010 on economic research; Marsden \& Gorman 2001 on labor markets; Pampel, Kruger \& Denney 2010, Pescosolido 1992, and Smith \& Christakis 2008 on health; and Sampson, Morenoff and Gannon-Rowsley 2002 on neighborhood effects). Well-designed studies have found network effects on employment out of college (Marmaros \& Sacerdote 2002) and mid-career (Laschever 2005), on schoolteachers' retirement decisions (Brown \& Laschever 2009), on immigrants' use of transfer programs (Bertrand, Luttmer \& Mullainathan 2000), on Finns' stock-market entry (Kaustia \& Knupfer forthcoming) and on CEO compensation packages (Shue 2011). Such studies have also reported network effects on Italian college students' graduation rates (DeGiorgi, Pellizzari \& Redaelli 2009), U.S. students' college performance (Fletcher \& Tienda 2009), and other educational outcomes. Networks have been shown to influence major life transitions as well, including child-bearing (Buhler \& Fratczak 2007; Kuziemko 2006), migration (Massey 1986; Massey \& Espinoza 1997; Amuedo-Dorantes \& Mundra 2007; Fussell \& Massey 2004), marriage (Adamopoulou 2011), and divorce (McDermott, Fowler \& Christakis 2011; Aberg 2009). Research has also revealed network effects on such health-related behaviors as contraceptive 
use (Kohler, Behrmann, \& Watkins 2001), participation in family planning programs

(Behrman, Kohler \& Watkins 2008), and smoking cessation (Christakis \& Fowler 2008), but not on cancer screening (Keating, O’Malley, Smith \& Christakis 2011).

Networks are also implicated in the adoption of risky behaviors (e.g., drug use, truancy, early initiation of sexual intercourse), especially among young people. When, as is usually the case, such behaviors negatively affect subsequent educational and occupational attainment, are negatively correlated with socioeconomic status, and spread through homophilic networks, network effects may exacerbate inequality. Using data from the National Longitudinal Study of Adolescent Health (Add Health), Card and Giuliano (2011) demonstrate effects of best friends' behaviors on ego's initiation of sex, smoking, marijuana use, and truancy. A seminal study of low-income urban youth (Case \& Katz 1991) found that parents' and sibling's experiences affected young people's risk of incarceration, drug abuse, and (for girls) early pregnancy. ${ }^{7}$ By contrast, a study of college roommates found more limited effects on drinking and no effect of roommate behavior on egos' drug use or sexual behavior (Duncan, Boisjoly, Kremer, Levy \& Eccles 2004). Research in criminology shows substantial impacts of peer networks on criminal behavior in adolescence and early adulthood (Elliott \& Menard 1996; Haynie \& Osgood 2005).

To be sure, the literature may overstate network effects. For one thing, it is likely that authors who find network effects are more likely to publish their results than those who do not. Moreover, research on network effects, and a fortiori on peer-group and neighborhood effects, is methodologically challenging, for at least two reasons (Aberg \&

\footnotetext{
${ }^{7}$ There is also a large literature demonstrating peer and neighborhood effects on risky behavior among youth that, while interesting, is less than conclusive as to network mechanisms, in that egos' personal networks are rarely random samples of peers or neighbors. For a review, see Dishion \& Tipsord 2011. For evidence that peer-effect models underestimate true network effects see Halliday \& Kwak 2007.
} 
Hedstrom 2011; Manski 1993; Harding, Gennetian, Winship, Sanbonmatsu \& Kling 2010). ${ }^{8}$

First, individuals in the same social network or peer group may be subject to similar unobserved environmental pressures or shocks. Unobserved-variable bias vexes most social-scientific models, of course. Many studies have employed ingenious methods to guard against specification error, e.g., by demonstrating varying outcomes for actors who should be subject equally to environmental effects but differentially to network influences (e.g. Hensvik, Asphjell \& Nillson 2011; Liu, King \& Bearman 2010; McDermott, Fowler \& Christakis 2011).

Second, selection into networks is a potential problem if individuals seek out others whose practices they wish to emulate, in which case the intent to adopt a practice produces rather than is caused by networks (Mouw 2002; Shalizi \& Thomas 2011). ${ }^{9}$ Researchers have addressed this problem by employing fixed-effects models with longitudinal data (a useful if incomplete solution), by undertaking fieldwork to explore the plausibility of endogenous selection (Watkins \& Warriner 2003), by employing sensitivity analysis to assess the robustness of particular network effects to varying degrees of confounding (VanderWeele 2011), and by identifying quasi-experimental contexts where ties result from choices that could not plausibly have been influenced by the practice in question (e.g. Marmaros \& Sacerdote 2002; Aberg 2009; Laschever 2005).

\footnotetext{
8 Manski (1993) mentions a third, "the reflection problem," that stems from the difficulty of allocating influence in a system in which several actors simultaneously influence one another in real time. Although this problem obscures the relative impact of peer behavior and peer attributes at the individual level, it is not relevant to assessing the contribution of network effects to inequality at the population level, so we do not discuss it here.

${ }^{9}$ Few studies have used longitudinal network data to compare the effects of influence and selection (both entering and leaving networks) on behavioral similarity. Those that have, have used data from schools and have reached different conclusions (based on different data sets). Cohen (1977) and Mercken, Snijders, Vartiainen \& DeVries (2009), for example, finds large selection effects in high-school peer groups, whereas McFarland \& Pals (2005) find little selection between middle school and early high school.
} 
Even when endogeneity does exist, the extent to which it is germane to the impact of networks on inequality depends on whether adoption of a new practice merely requires awareness and interest, or if peer support is necessary for that interest to be transformed into behavior. Adoption of a new practice often proceeds in two stages: The actor first becomes aware of the practice and wishes to adopt it; and the actor then turns to peers for assistance in doing so. When adoption is easy, and the actor does not need social support to fulfill the desire to adopt, the analyst may find spurious network effects if actor prefers to associate with other adopters. When adoption is difficult - where an actor requires assistance to adopt successfully or when a practice's rewards accrue to an actor by virtue of persistence in a network (e.g. joining a food buying co-op) -- the situation is more complex. In this case, the actor's decision to adopt is not affected by network ties, as these were formed as a consequence of the actor's decision. The actual adoption, however, is a product of network effects, in that it could not have occurred had the actor not succeeded in forming new ties. In this latter case, network effects will increase inequality in rates of adoption of a practice at the population level, even if they cannot be said to have "caused" adoption at the level of the individual. Ultimately, a more satisfactory approach may be to model the relationship between networks and behaviors not as causal, but as co-evolutionary, each side (networks and behaviors) constituting an environment for the selection of the other.

These methodological concerns are important. Nontheless, the weight of evidence supporting network effects, much of it from studies employing credible means to address potential problems, convinces us that peer networks influence many kinds of behavior, including practices with significant implications for social inequality. 


\section{Network and Peer Interaction Effects}

The mere existence of network effects on adoption of a practice (if the network is homophilous with respect to individual characteristics associated with adoption) is sufficient to render it plausible that networks exacerbate intergroup inequality in that practice's adoption. This will only be the case, of course, if those groups are defined on the basis of characteristics that serve both to increase individual-level odds of adoption and as bases for homophily. Given the wide range of cases for which such characteristics as education, race or income satisfy these conditions, this is a modest qualification.

An emerging set of network-effects studies go beyond merely documenting effects, however, to demonstrate that such effects interact with measures of individual advantage such that high-status people benefit from network effects more than their lower-status counterparts. In other words, such studies identify practices for which networks may exacerbate inequality in two distinct ways - first, by augmenting the impact of individual endowments; and, second, by doing so disproportionately for the already advantaged. This second-level effect is potentially consequential, as it may extend the scope conditions for the inequality-exacerbating mechanisms considerably by suppressing the ability of lowerstatus members of heterogeneous peer networks to serve as bridges diffusing access to a practice beyond the circle of the initially advantaged.

Intergroup variation in returns to networks has been explored most thoroughly in work on labor markets. Several papers report that the association between using networks to find jobs and job quality is stronger for high-SES than for low-SES workers (Lin 1999; Ioannides \& Loury 2004) and for men than for women (Ensel 1979). Other evidence indicates that one's peers' employment status affects one's own more strongly for whites 
than for African-Americans. Holzer (1987) argues that between 24 and 38 percent of the difference in employment rates between white and Black youth is attributable to superior returns to the job referral networks of the latter (and see also Bortnick \& Ports 1992). Similarly, Korenman \& Turner (1996) report that higher returns for whites than Blacks to the use of personal networks for job-seeking account for a significant share of racial inequality in wages.

Indications that the relatively privileged benefit disproportionately from peer effects even in heterogeneous groups have also been observed in education, though interactions are weaker and less consistent (Epple \& Romano 2011). Sacerdote (2011:260) concludes from his literature review that "students at the high end of the ability distribution experience the largest peer effects from high ability peers." A study of Israeli elementary-school classrooms reports that that the number of exceptional achievers positively affects the learning of high-achieving students but not of other children, whereas the number of unusually low achievers disproportionately affects the performance of low-ability children (Lavy, Paserman \& Schlosser 2007). Exploiting a situation in one large school district in which high numbers of random school reassignments produced a quasi-experimental design, Hoxby \& Weingarth (2006) likewise found that the positive effects of highachieving peers were concentrated among other high achievers. Hoxby (2000) similarly reported that peer effects on performance operated more strongly within racial groups than between them. By contrast, some studies have found that high-ability peers affect the performance of low- or medium-ability peers as well as one another (Burke \& Sass 2008). Unfortunately, all of these studies focus on colocation in the same classroom or school, without drawing upon actual network data. Thus where interactions have been found, it is 
unclear whether they reflect a disproportionate positive impact of networks on the already advantaged. An alternative interpretation consistent with these results is that network effects, not peer effects, drive achievement, and that students sort themselves into homogeneous groups within heterogeneous schools or classrooms (Carrell, Sacerdote \& West 2011).

Differential network effects based on SES or ethnicity have been reported in several other domains. In a study of the use of family planning programs in two African countries, Behrman, Kohler \& Watkins (2008) found that network effects were stronger for women with higher levels of formal education. Several migration studies report that men's migration choices are influenced more by network alters than those of women (Curran, Garip, Chung \& Tangchonlatip 2005; Kanaiaupuni 2000; Gramusk \& Pessar 1991) and that men benefit more than women from ties to co-ethnics in destination (Hagan 1998; HondagneuSotolo 1994). In the domain of health, Christakis and Fowler (2008) report that highly educated friends influence the decision to stop smoking more than less educated friends.

We feature this research because it indicates that under the right conditions, highstatus people benefit disproportionately from network effects not just because they are more likely to have network peers who have already adopted beneficial practices, but furthermore because they are more susceptible to positive influences, even when their peer networks are socially heterogeneous. Indeed, either condition - if individual endowments are associated with having more prior adopters in one's network or with a higher susceptibility to influence from as many previously adopting network alters one has - would suffice to produce surplus inequality. The combination would boost inequality yet further. Outside of the labor-markets field, evidence on differential influence is scattered, and it is 
difficult to know whether researchers have tested interaction models but failed to report them due to negative findings, or whether such models are rarely included in analyses. In any event, further study is warranted.

\section{Direct Models of and Evidence on Network Effects on Intergroup Inequality}

Thus far we have examined research that bears indirectly on the contribution of networks to inequality in access to or adoption of practices that positively affect one's life chances. In this section we discuss a few studies that either model this process or present evidence about changing inequality directly.

We begin with the models, one of the earliest of which is Montgomery's (1991) social-learning model of a labor market in which employers may recruit workers through referrals or through want ads, workers take jobs through referrals when available and through formal channels otherwise, employers who recruit through referrals pay better wages than those who do not, and employers can observe the productivity of workers $e x$ post but not ex ante, and also assume (correctly, given homophily bias built into the model) that workers contacts will be similar in productivity. Montgomery demonstrates that wage differentials between high-ability and low-ability workers expand over time. Adding social characteristics that are uncorrelated with ability but with respect to which contacts are also homophilous to the model, he demonstrates that if employment rates are lower for members of one group (for example women) at the start, wage inequality will become greater over time. This simple model captures the major outlines of the mechanism in which we are interested and, moreover, could be extended to situations in which employers make ex ante assumptions about classes of workers (for example, underestimating the productivity of women and African-Americans relative to men) at time 1, which would also 
yield greater inequality over time. Using a more complex model that focuses on the contribution of networks to the quality of the worker job match, Arrow and Borzekowski (2004) reach similar conclusions.

Calvó-Armengol and Jackson (2004) present a more elaborate finite-state Markov social-learning model of employment in which exogenously provided job information is passed among network members, who act upon it to improve their positions. Agents may be "fired" (randomly) and drop out of the labor market when discounted expected future income falls below the cost of labor-market participation. Employed agents who receive information about job opportunities pass it on to agents to whom they are tied, who pass it on if already employed or take the job if unemployed. Therefore, the greater the percentage of network alters who are employed, the higher is ego's probability of learning about (and taking) a job. The authors report that "small differences in initial conditions can lead to large differences in drop-out rates and sustained differences in employment rates" (2004: 247). They contend that their model provides insight into long-term differences in labor-market participation by blacks and whites in the U.S.

DiMaggio and Garip (2011) present a moving-threshold model of the influence of network externalities on Internet adoption, in which each agent has a reservation price at which it will subscribe to home Internet service. The reservation price is a function of income and the percentage of network alters who have already adopted. Internet price is a declining function of adoption levels. Agents were sampled from the 2002 General Social Survey to produce realistic distributions and covariance of income, race, educational attainment, and social network size. After each period, each agent compares the price of Internet service to its reservation price and adopts or declines to adopt. Adoption occurs 
due to a price decline to below ego's reservation price, an increase in ego's reservation price due to adoptions by network alters, or a combination of both. The model was run without externalities (the impact of percentage of adopters in network was set at 0), with global externalities (any adoption affects all potential adopters equally), and with local externalities (only one's network alters' adoptions matter) and five levels of homophily. ${ }^{10}$ Without externalities adoption never took off and usage rates increased minimally. Diffusion with externalities hewed to the familiar sigmoid curve (starting slow, accelerating, then tapering off). Penetration was greatest under global externalities, with similar results from the model positing local externalities without homophily. As homophily bias increased, the diffusion curve's slope steepened, but overall penetration declined and intergroup inequality (by race, income level, and education level) increased monotonically. An advantage of the threshold approach (Granovetter 1978) is the ease with which different mechanisms can be modeled by simply changing the network measures and/or the functional form of the equation specifying the network effect on reservation prices.

Such models explicate the ways in which networks may aggravate inequality, and even suggest strongly (by articulating inferences based upon relatively well established findings) that they do so; but they cannot provide direct evidence of an effect. Indeed, relatively few studies have yielded directly relevant empirical evidence. DiMaggio and Garip (2011) produced what may be the only published empirical study that focuses as its prin-

\footnotetext{
10 The mechanism is described as based on "network externalities," which the authors defined broadly. Given our more restricted definition of externalities in this paper, the use of the percentage rather than the number of adopters in one's network may be considered more appropriate (for reasons to be explained below) for a model of normative influence than of network value (i.e. pure externalities). At the same time, the rationale for using the percentage measure - i.e., that the value of being able to communicate through a new channel with a given contact will be greater for people with few friends than for those with many - is sufficiently persuasive that it underscores the difficulty of matching measures to mechanisms.
} 
cipal concern on change in inequality as a function of network effects. The authors studied economically motivated temporary migration from 22 Thai villages to Bangkok and other urban centers between 1972 and 2000, a period during which such migration grew substantially from similarly low levels in all villages. After identifying peer and network effects on migration, the authors demonstrate that the villages where homophily was greatest diverged most markedly from the group mean, exhibiting significantly higher variance (inequality) in 2000 migration rates than villages with less homophilous networks. Consistent with Calvó-Armengol and Jackson's employment model, the analyses demonstrate that a combination of network effects and social homophily can generate inequality even where initial differences are very modest. In related work, Curran, Garip, Chung \& Tanchonlatip (2005) found evidence that differences in migration propensities between men and women were augmented by local network effects in homogeneous networks.

Other relevant findings are scattered over several literatures. Goolsbee and Klenow (2002) report increasing divergence (net measurable urban differences) in computer ownership rates in U.S. cities during the 1990s, which they attribute to the effect of network externalities. In a cross-national study of product diffusion, Van den Bulte and Stremersch (2004) find that the relative importance of endogenous (network) effects on adoption as opposed to exogenous effects (e.g., of external shocks or marketing campaigns) on adoption was associated with the extent of social inequality - an intriguing result consistent with the notion that networks aggravate inequality but also with the authors' interpretation emphasizing heterogeneity in the propensity to adopt. Christakis and Fowler (2008) report polarization of social networks over time with respect to smoking cessation. Shue (2011), exploiting random assignment of Harvard Business School (HBS) students to sections to rule 
out selection effects, reports that, among students who go on to become CEOs, peer effects increase income variance by 20 to 40 percent (with variance increasing fastest one year after major HBS reunions). Duflo and Saez (2002) report greater than expected variance among libraries in employee participation in retirement savings plans (and in the providers that participants chose), and note that differences were even stronger among groups defined by age, gender, and organizational authority. Thus models and empirical studies of labor markets, new-product diffusion, migration, economic behavior, and health-related behavior all suggest that network effects exacerbate inequality when groups vary in initial endowments, and that they can produce inequality when initial endowment are similar.

We believe we have built a convincing case for the proposition that social networks may exacerbate inequality in the adoption of beneficial practices. Homophily is ubiquitous. Empirical evidence supporting the importance of network effects is widespread in many research fields. Moreover, evidence indicates that the already advantaged not only benefit directly from association with their peers, but may, in some cases, be more susceptible to social learning than persons of lower status - so that pure network effects are augmented by interactions between network measures and individual endowments. Formal models demonstrate how the concatenation of homophily and network effects generate intergroup inequality over time, and a limited empirical literature is consistent with the results of these models. We hope that the reader agrees that this evidence is sufficient to establish the plausibility of the proposition that network effects are a significant source of intergroup inequality, and to stimulate research into that phenomenon. 


\section{FOR WHAT PRACTICES DO NETWORKS AGGRAVATE INEQUALITY THE MOST?}

At this point, however, we wish to complicate and qualify this broader argument, focusing on how characteristics of the practices available for adoption will influence the extent to which network effects exacerbate inequality.

\section{Simple vs. Complex Contagion}

We have already articulated several scope conditions necessary for social networks to increase inequality in the manner proposed: actors must be free (given adequate resources and information) to adopt or not adopt a practice that may help them get ahead; adoption must be influenced by social networks; and those networks must be characterized by homophily with respect to individual characteristics positively associated with adoption, or subject to random or exogenously determined inequalities in initial adoption rates.

Here we suggest that there may be a fourth scope condition --- that the argument applies to what Centola and Macy (2007) refer to as "complex contagions" - contagions for which adoption is a relatively hard sell, such that a potential adopter requires contact with multiple prior adopters before deciding to adopt. The authors contrast complex contagions to simple contagions, characteristic of the flow of highly communicable diseases or of information, where a single contact produces an effect. Simple contagions are efficient: you do not need two people to tell you that milk is on sale at Safeway this week to act on the information. By contrast, complex contagions require reinforcement from two or more trusted associates. Before you sign up for an Occupy Wall Street or Tea Party rally, or move to another state to find employment, you may require encouragement and persuasion from several friends. If we translate Centola and Macy's typology of network effects (2007: 70708) to the three mechanisms noted at the beginning of this paper, we see that simple con- 
tagions are most likely to play a role in social learning processes. Diffusion driven by externalities is necessarily complex (I am unlikely to invest in a communication device with which I could contact only one friend), as are processes driven by normative influence (e.g., most people will need assurance or persuasion from multiple contacts before joining a sect or quitting smoking). We explain why we doubt that network effects in simple contagions produce surplus inequality in more detail below. But the intuition is this: Few persons' networks are entirely socially homogenous and almost everyone has a few contacts different from oneself on at least one or two dimensions. Even if such ties are few, they can facilitate the flow of information between otherwise isolated network neighborhoods, so that practices adopted on the basis of a single contact tend to spread broadly and rapidly. What Makes a Contagion Complex?

To put it somewhat differently, the more complex the contagion, the greater the extent to which network effects may produce surplus inequality. Several characteristics of a practice render it subject to complex rather than simple contagion.

Risk and uncertainty. The more people doubt a practice's efficacy or face risk in adopting it, the more reinforcement their choice will require. For example, the practice of international migration should spread by complex contagion due to the risks inherent in moving to a new and potentially dangerous environment (Massey \& Espinosa 1997).

Complexity. Practices also vary in the ease with which a novice can pull them off and the social support necessary to do so credibly. Employing a potentially useful technology (e.g., a new software package) may require concentrated peer assistance in the early stages (DiMaggio, Hargittai, Celeste \& Shafer 2004). Or a practice may be complex due to the social skill it requires: e.g., credibly claiming a new social identity (McFarland \& Pals 2005). 
Observability. Strang and Soule (1998: 269) call attention to importance of observability. How easy is it to tell if a network peer has adopted a new practice? How effectively can one observe the practice in operation? To what extent can one observe its consequences? Consider, for example, the difference between planting a new crop (relatively observable to other members of an agricultural community) and using a new method of birth control (relatively unobservable) (Behrman, Kohler \& Watkins 2002). The lower the probability that a given peer who has adopted will reveal (intentionally or unintentionally) that she or he has done so, the less likely a practice is to spread by simple contagion.

Legitimacy. Rossman (2011) argues that a new practice that is an instance of an already accepted practice (e.g., downloading a tune in an established genre) spreads by simple contagion, whereas a practice that has not yet been fully institutionalized requires more substantial peer support, especially if adoption is unobservable.

Sustainability. Practices also vary in the extent to which, once initiated, they are self-sustaining, in contrast to requiring continual peer support. Where network externalities drive adoption (e.g., joining Facebook) or where the key mechanism is normative influence and the behavior is observable, the practice requires on-going social support. By contrast, having one's children receive required vaccinations may be more likely to spread by simple contagion (other things equal), as it is a one-act that is not subject to sustained peer influence.

To summarize: We expect network effects to exacerbate intergroup inequality in the diffusion of a useful practice to the extent to which that practice is risky, complex, difficult to observe, weakly institutionalized, and unsustainable without social support. 


\section{A TAXONOMY OF NETWORK EFFECTS}

The previous section distinguished among types of behaviors, focusing on the characteristics likely to facilitate or impede their spread across network ties. This section focuses on differences among mechanisms of network influence, classifying mechanisms according to the functional forms that best describe the manner in which they shape behavior.

The extent to which network effects exacerbate intergroup inequality will vary, even among the most complex contagions, depending on the mechanisms through which network effects operate. ${ }^{11}$ Yet, as Durlauf \& Ioannides note (2010:458), researchers often neglect to specify mechanisms or fail to match measures and functional forms of network influence to their theoretical intuitions. Here we discuss the implications for measurement of the most important mechanisms. The discussion is summarized in Table 1, which lists three primary mechanisms and their major variations (including hybrids), and describes each mechanism's fingerprint (a distinctive functional form connecting network properties to individual-level effects, by which it may be recognized empirically).

We use mathematical notation to clarify the differences among the three kinds of network effects. For each, we assume that $y_{i t}^{*}$ denotes individual $i$ 's latent reservation price for adopting a practice at time $t^{12}$

$$
y_{i t}^{*}=h\left(x_{i t}\right)+f\left(w_{i t}^{T} y_{t}\right)+\varepsilon_{i t}
$$

$$
i=1, \ldots, N
$$

${ }^{11}$ We do not claim that this list is exhaustive and we recognize that networks induce adoption of many practices through more than one mechanism. To take one example: Having married friends may raise the probability of marriage through externalities (the value of the network once one is married), social learning (from one's friends experience or help in finding a spouse), and normative influence (social pressure). Or bright and high-status classmates may produce externalities (a peaceful classroom in which the teacher can spend more time on instruction), induce social learning (help in understanding new material), or exert normative influence (encouragement to study or take a difficult course).

${ }^{12}$ Researchers often observe the binary adoption outcome $y_{i t}$ (equals 1 if $y_{i t}^{*}>0$ and 0 otherwise), and model it with a logit or probit specification to estimate network effects. Manski (1993) notes the identification problems in this strategy. 
where $h\left(x_{i t}\right)$ denotes the contribution of individual characteristics related to adoption, and $\varepsilon_{i t}$ is the error term known to the individual but unobserved by the researcher. $y_{t}$ is a binary vector of adoption outcomes of all individuals at time $t$ (where each entry is a function of corresponding individual's latent reservation price $y_{i t}^{*}$ ) and $w_{i t}$ is a vector that indicates individual i's network ties at time $t$, where non-existing ties are represented with a zero entry.

Table 1 about here

\section{Network Externalities}

Network externalities exist when the value of a practice increases as a function of the number of prior adopters. This feature - the tendency for each additional adopter to add value to the network and thus increase the size of the network effect -- is its fingerprint. Of interest here are local network externalities: cases in which the relevant adopters are those to whom ego is directly tied, as is typical in the case of communications technologies.

Network-externality effects may be (a) a linear function of the number of peers who have adopted previously (e.g., in certain forms of voluntary labor-pooling like food co-ops); (b) a logarithmic function (if each additional peer over a certain number provides less incremental value than the last), probably characteristic of the value of communications technologies to individual users; or (c) an exponential function (if the value of the network lies not only in ego's access to each peer, but in ego's access to interactions among ego's peers), typical of user communities and successful online social networks (e.g., Facebook, for its devotees). Given competing technologies, each subject to network externalities 
(e.g., Windows vs. Mac OS, or Excel vs. Lotus in the 1980s), one also may observe a mixed mechanism (part externalities, part normative influence) (Brynjolfssen \& Kemerer 1996). When observation is difficult, the number or percentage of adopters should be multiplied by the probability that ego will be aware of the adoption status of a network tie. Note that because the value of the network is a function of its size, network influences are ongoing and defections from a network reduce its overall value. Under these conditions, members of groups least likely to adopt a practice are also disproportionately prone to abandon it.

To model local externalities, $w_{i t}$ entries (in Eq. 1 above) may be normalized by the total network size or may be weighted by network proximity (e.g., to reflect the probability of observing the adoption outcome of the corresponding alter). In the former case, $w_{i t}^{T} y_{t}$ would equal the percentage of adopters; and in the latter, a weighted sum of observed adopters in an individual's network. Finally, $f()$ can be a linear, logarithmic or exponential function relating the total number or percentage of all or observed adopters in an individual's network to the individual's reservation price. ${ }^{13}$ (See Brock and Durlauf (2001) for a similar formulation.)

\section{Social Learning}

In social learning, adoption occurs when ego becomes aware of a behavioral option and convinced that it is efficacious and entails an acceptable level of risk. Because at some point one has learned enough to make a decision (or has enough social support to sustain it), the fingerprint of social-learning processes is the existence of step functions or thresh-

\footnotetext{
${ }^{13}$ DiMaggio and Garip (2011) use a similar model, but allow the individual characteristics and network effects to interact. We opt for a simpler model here for the sake of demonstration. We also focus on contemporaneous network effects, but a more general model could incorporate lagged effects as well.
} 
olds in the relationship between the number of peers who have adopted and the strength of the network effect.

When the payoff of a course of action is obvious, as in instances of simple contagion, social learning may be based on a single contact (so that network effects can be expressed as the probability that at least one network tie will provide information). We suspect, however, that most social learning, at least of practices that are consequential for an actor's welfare, requires information that is thick with detail and validated by more than one tie (i.e., as in complex contagions). Thus someone searching for a cancer specialist or considering whether to purchase an electric car is likely, if she or he can, to discuss the options with several experienced peers before making a decision. In this instance, then, action is likely to be triggered when the $n$ of network members who have already adopted a practice (who have used a given doctor or who own a Prius), or who have in some other way learned enough to provide rich information to ego (who have had to find a medical specialist for a loved one, or who work in automotive engineering) has reached a threshold that exceeds unity. This is also likely to be the case where successful adoption of a practice (e.g., using a new form of birth control or becoming a new parent) requires not only advice but also support during the adoption practice itself. Finally, in some instances, where adoption entails a commitment to a new practice that poses recurrent challenges (e.g., migrating from farm to city for work or seeking a professional degree), network effects are likely to be continual and efficacious as some function of the total size of the relevant network, often declining in slope as the network grows larger. In this sense, ongoing forms of social 
learning related to significant life transitions may be analytically difficult to distinguish from pure network externalities. ${ }^{14}$

For purposes of modeling social learning, $f()$ is a step function that obtains a positive value if $w_{i t}^{T} y_{t}$ (capturing the total number or percentage of all or observed adopters, as in the network externalities case) exceeds a specified threshold, $T_{i}$, for individual $i$.

\section{Normative Influence}

A third class of mechanisms, normative influence, works not by affecting a practice's value directly, or by providing information or assistance, but through the application of positive and negative sanctions upon network members. Like pure externalities, normative influence generates complex contagions (it requires the engagement of numerous network alters) and entails ongoing effects. Unlike pure externalities, however, normative influence is a function of both peer support for a course of action and of the density of ties among those peers (on which their ability to exert influence on ego is in part conditional). The relevance of the ego network's internal structure is the fingerprint of normative influence processes (Haynie 2001; Kohler, Behrman \& Watkins 2001).

We distinguish here between two types of normative influence. In both, at least some of ego's network alters attempt to induce ego to adopt a new behavior by providing approval for actions consonant with the behavior and negatively sanctioning inconsistent

\footnotetext{
${ }^{14}$ Certain forms of matching processes (Granovetter 1974) can be treated as forms of social learning, albeit ones in which the payoff (a job placement) is the product of a bilateral choice process. In simple information sharing in job-referral networks, ego passes information about an opportunity to a contact, who may use it, drop it, or pass it on (Boorman and Levitt 1982). In this case, the strength of network effects may approximate a function of the number of persons in ego's network, adjusted for the probability that each will have useful information, itself a function of their position in broader social networks. In general, alters who are higher-status than ego provide better leads (Lin, Ensel \& Vaughn 1981). In some cases, such a process can occur so frictionlessly as to represent a form of simple contagion. By contrast, matching processes that require active brokerage (e.g., vouching for a job candidate or setting up a blind date) represent a more distinct mechanism.
} 
behavior. ${ }^{15}$ But in the first type, ego's alters are divided between those attempting to induce generally approved behavior (e.g. smoking cessation or dieting) and those who are indifferent but not hostile. Observation of friends' behavior may also serve to produce a plausibility structure (Berger and Luckman 1966) for behaviors that might otherwise seem illegitimate or difficult to imagine (e.g., divorce [McDermott, Fowler \& Christakis 2009]).16 In either case -- persuasion or legitimacy-through-observation -- adoption occurs when the group of alters supporting or modeling change reaches a critical mass (Marwell and Oliver 1993) sufficient to induce change. By contrast, the second type of normative influence entails struggle between two sets of opposing network alters, each applying positive and negative sanctions to sway ego to its side (e.g., political partisans). In the former case, adoption occurs when the percentage of network peers supporting a practice reaches some critical mass. In the latter, the probability of adoption of a practice is a function of the difference in the proportion of network alters adhering to each option. In each case, the relevant percentages must be weighted by the density of ties within each group, as better acquainted peers will be better able to coordinate their influence. ${ }^{17}$

\footnotetext{
${ }^{15}$ Some economists contend that networks exert social influence because individuals have a "taste for conformity" (Patacchini \& Zenou 2011) that leads them to mimic the majority of their network peers when practices are divided. Although this sometimes may be a useful simplifying assumption, we doubt that such a taste exists, so do not treat this as a distinct mechanism. Evidence that young people do like to conform, but that the process is more complicated than the simple taste-for-conformity thesis suggests, comes from social psychological work on pluralistic ignorance, which indicates that students adjust their behavior toward what they believe (often incorrectly) to represent the norms of their peers (Prentice \& Miller 1993).

${ }^{16}$ Rossman (2012: 96-112) distinguishes between the diffusion of the notion that a practice is legitimate and the diffusion of the practice itself, contending that an instance of an already institutionalized category (e.g., listening to a popular song in an established genre) will diffuse far more easily than a practice that lacks prior categorical legitimacy (see also Strang \& Meyer1993 and Hsu, Hannan \& Kocak 2009). Note, however, that a new practice is often legitimated at the societal level, often with assistance from the mass media -- in effect, it is a global externality -- rather than separately within specific networks. Local network effects on legitimacy are probably strongest for behaviors that are private and difficult to observe.

${ }^{17}$ As Centola and Macy (2007: 711) have written, the distinction between number of alters and percentage of alters "reflects an underlying (and often hidden) assumption about the influence of nonadopters. Fractional thresholds model contagions in which both adopters and nonadopters exert influence, but in opposite direction...In contrast, numeric thresholds model contagions in which nonadopters are irrelevant."
} 
Under normative influence, the argument of $f(), w_{i t}^{T} y_{t}$ is replaced by $w_{i t}^{T} y_{t}-u_{i t}^{T} z_{t}$.

Here $y_{t}$ indicates a subset of adopters who are passionate about inducing a practice and $z_{t}$ indicates a subset of nonadopters who are passionate about preventing the practice. $w_{i t}$ and $u_{i t}$ are vectors that indicate individual $i$ 's network ties at time $t$ to the subsets of passionate adopters and nonadopters, respectively, where non-existing ties are represented with a zero entry. $w_{i t}$ and $u_{i t}$ entries are typically normalized by the respective network size and potentially weighted by the respective network density. (One might also model heterogeneity into the network, with influence of alters varying with their tie strength to ego or network centrality.) Similar to the social learning case, $f()$ is a step function, which

obtains a positive value if $w_{i t}^{T} y_{t}-u_{i t}^{T} z_{t}$ exceeds a specified threshold, $T_{i}$, for individual $i$. Note that in the absence of polarization on the practice, $z_{t}=0$, and $f()$ takes $w_{i t}^{T} y_{t}$ as the input. Mechanisms implicated in complex contagions of beneficial behavior in networks characterized by homophily are likely to exacerbate intergroup inequality; and different mechanisms are likely to do so in different ways. Young (2009) derives the implications of several mechanisms for the shape of diffusion curves (see also Rossman, Chiu \& Mol 2008), but under limiting assumptions (an infinite population and random ties) and without attention to implications for inequality. Clear specification of network mechanisms is a necessary first step, but understanding how different mechanisms shape inequality will require additional modeling and empirical research.

\section{CAN NETWORK EFFECTS REDUCE INEQUALITY?}

Thus far, we have focused exclusively on mechanisms by which networks may produce higher levels of inequality than one would expect based on differences in individual endowments. We have noted that for this to occur, high-status people must have an initial ad- 
vantage in adopting a beneficial practice; networks must be characterized by homophily; and the probability of adoption by any actor must be increased by the prior adoptions of his or her network peers. It follows from this that networks may reduce inequality under two conditions: first, if initial advantage with respect to a beneficial practice is negatively correlated with SES or other measures of privilege (inverted advantage); and, second, if homophily is insufficient to amplify initial advantages.

\section{Inverted Advantage}

By inverted advantage we refer to cases in which a group that is subject to discrimination, social isolation, or both acquires a niche that becomes profitable or prestigious. Stylized examples include the success of French Canadians in hockey (Belanger 1996), of African Americans in basketball and rap music (Edwards 1979), and of Jews in the early $20^{\text {th }}$ century film and popular music industries (Gabler 1989). To be sure, non-network mechanisms (including discrimination in alternative pursuits or social-identity effects unrelated to the behavior of network peers) play roles in such cases; but if choices to develop skills that may lead to professional careers are influenced by social learning or peer modeling, then it follows that network effects would, in small ways, oppose broader patterns of inequality.

Alternately, network effects may tend to reduce intergroup inequality in valued outcomes if the initially privileged are more likely to participate in such harmful activities as specific forms of drug abuse (Abelson \& Miller 1985) or investment in Ponzi schemes. Such activities may spread through networks if short-term rewards negate considerations of long-term harm (as is the case for addictions); or if social-influence processes yield social side payments sufficient to outweigh long-range risk. In such cases, network effects could limit inequality by producing additional harms to the socioeconomically advantaged. 


\section{Limited Homophily}

Cases of inverted advantage are relatively few and may affect intergroup inequality trivially, if at all. By contrast, cases in which network homophily is insufficient to bias adoption of beneficial practices toward the initially advantaged may be more important, more interesting, and more susceptible to policy intervention. Departures from homophily in networks occur when ties are formed on the basis of complementary attributes (gender in heterosexual marriage) or skills (in organizational teams); when actors intentionally form ties to alters who are different from themselves (e.g., in order to benefit from social learning or externalities); or because salient status characteristics are imperfectly correlated (as is almost always the case).

Weakly correlated status parameters are most likely to reduce inequality in the case of simple contagions in small worlds. When adoption of a beneficial practice spreads through simple contagion - when a single contact is sufficient to induce action - network effects, even given high levels of homophily, are unlikely to exacerbate inequality. First, as Blau (1977) demonstrated, as long as status and identity dimensions with respect to which networks are homophilous (e.g. education, income, or race) are incompletely correlated, homophilous choice with respect to any one dimension will bring one into contact with actors who vary on others. Consequently some network ties serve as bridges among groups differentiated by relative privilege.

Second, such patterns are likely to generate "small worlds" - global networks characterized by concentrated regions of densely connected actors united by bridging ties that facilitate the rapid spread of information (Watts 1999). Where contact with a single prior adopter is sufficient to induce action (i.e., where costs of adoption are low and benefits ev- 
ident) and the strength of network effects does not depend upon ego's status, practices may move across intergroup and status boundaries more quickly than they would diffuse based on individual differences alone, even if high levels of homophily produce relatively dense and homogenous ego networks. Consistent with this view, Golub and Jackson's (2011) computational model reveals no impact of homophily on the flow of information through a network, but indicates that homophily significantly impedes consensus formation (a process analogous to complex contagion). Different combinations of homophily bias and adoption thresholds (the number of contacts required before a practice is adopted) are likely to have varying effects on inequality. Identifying the tipping points at which network effects on inequality turn negative is an important research priority. ${ }^{18}$

A variant of this may occur when networks provide assistance to their members in learning about and obtaining good jobs. In such matching processes, the probability that any given one of ego's contacts will provide useful information is, first, a function of that actor's position in the broader social structure (of the probability that he or she has access

18 The matter is complicated by a lack of research on how choice homophily operates in practice, that is, on the choice processes that constitute choice homophily or of the constraints that generate structural homophily, even though different processes will generate different results in terms of the distribution of attributes within groups. Imagine, for example, a female Hispanic college graduate who prefers to associate with people like herself in gender, nationality and educational attainment. That preference could take the form of (a) a desire to maintain friendships with people identical to herself on all three dimensions (so that, in effect, female Hispanic college graduate acts as a single category; or (b) a tendency to gravitate to others based on a (possibly weighted) average of those three attributes; (c) a quota system, such that she recruits friends in each of the three categories, with little regard for those persons' positions on other salient dimensions; (d) or an exclusion principle (whereby she maximizes similarity under the constraint that she will not form ties to alters in a particular differing category, e.g. high-school dropouts). Reflection suggests that a world in which "homophily" referred to the first of these approaches would generate the most homogeneous friendship nets with the most strongly correlated parameters - which, other things equal, would generate the strongest intergroup differences on the relevant dimensions. The third approach would generate the least homogenous networks, the least strongly correlated parameters, and weakest intergroup differences. Such differences are not captured by conventional measures of homophily bias (which specify the probability of homophilous choice, not the meaning of such a choice). Additional research is needed, as well, on the relationship between homophily and triadic closure - under what conditions, for example, individuals tend to segregate their network based on the traits they share with different alters, as opposed to bring together alters with different characteristics (possibly creating bridges) (but see Kossinets \& Watts 2009). 
to information useful to ego) and, second, of the probability that he or she is inclined to use that information to assist ego (Smith 2005). This second condition produces what might be called the paradox of weak ties: as Granovetter (1974) argued, acquaintances to whom job-seekers are weakly tied may produce the most useful information precisely because they are more likely to be aware of new opportunities than are ego's close friends; yet the very acquaintances who can help most may be least willing to take the risk of vouching for a potential employee. We suspect that under certain conditions, what might be called the "paradox of weak ties" may generate greater equality than would be observed based on individual differences alone. The reason for this is that an agent seeking a job or other match may obtain the most effective assistance from "weak ties," who are ordinarily less sociodemographically similar to ego than those to whom ego is strongly attached (Rivera, Soderstrom \& Uzzi 2010). Put another way, network effects that work through matching processes are especially likely to involve sociodemographically different network alters. When status differences between match-makers and match-takers are significant, and highstatus alters are willing to use their information or contacts to help lower-status associates, networks could moderate intergroup inequality. Additional research is necessary to identify the network structures and labor-market conditions for which this is the case.

\section{PRIORITIES FOR RESEARCH ON NETWORK EFFECTS ON INEQUALITY}

Six research priorities strike us as especially important:

1. Specify mechanisms and test alternative specifications. A first priority is greater rigor in specifying the mechanisms through which effects occur, identifying likely effects on the basis of both theory and, when possible, fieldwork (Watkins \& Warriner 2003); and comparing the results of models based on alternative specifications, in order to identify the 
mechanisms that are most important for the diffusion of particular classes of phenomena. Several fine papers compare two potential mechanisms, but accumulation of knowledge is impeded by the absence of standard nomenclature and by the absence of systematically broader comparisons.

2. Employ computational models to understand better the implications for social inequality of different network-effect mechanisms, to identify the conditions under which network effects most severely exacerbate inequality as well as the conditions under which they may ameliorate it, to tease out interactions between types of mechanism and types and degrees of homophily, and to investigate mixed forms where externalities are both local and global. As demonstrated by Calvo-Armengol \& Jackson's (2004) recommendation to focus resources on particular clusters and neighborhoods of the poor (to produce critical mass for change processes that could ramify to other networks), such research can produce not only to fundamental scientific understanding but to policy-relevant knowledge as well.

3. Conduct empirical research on network effects with appropriate data in a variety of contexts and on adoption of a range of goods and practices. By appropriate data we mean, first, data on actual network ties (as opposed to data on copresence [as in the peer effects literature], which may or may not serve as a proxy for interaction); and, second, data with repeated observations of social networks, adoption of particular beneficial practices, and change in intergroup inequality. Such studies should use case-specific inferential reasoning to ask not just "are there effects?" but "what mechanisms produce these effects," and test both for network effects on the probability of adoption and network effects on returns to adoption, as well as for differences in the slope of these effects for different kinds of actors. 
4. Differentiate among types of relationship. While limited availability of appropriate data often leads researchers to abstract away differences among types of ties, the few studies that attend to such differences suggest that differences are consequential. How does the influence of kin differ from that of friends or co-workers (Christakis \& Fowler 2008)? Under what conditions are weak ties more influential than strong (Krieger \& Haynie 2011)? When do unreciprocated friendship ties matter (Faris \& Ennett 2011)?

5. Study interactions between networks and institutions: Some institutional configurations may dampen the ability of social networks to exacerbate inequality: For example, networks may be less important to labor-market outcomes when jobs are plentiful and equal opportunity rules enforced than when labor markets are weak and discrimination tolerated; networks may have weaker effects on technology adoption if technologies are made widely available in such public settings as community centers or libraries; networks may matter less for access to government services when agencies invest more in outreach; and networks may have less influence on investment decisions when employee investment accounts are governed by opt-out (as opposed to opt-in) decision rules. Conversely, networks may sometimes interact with institutional factors to amplify long-term increases in inequality: Johnson and Raphael (2009) demonstrate that the interaction of incarceration policies with racial homophily in sexual networks accounts for most of the black-white difference in HIV infection rates. Similarly, individuals who benefit from network effects in high school are more likely to attend elite institutions that provide them with even richer social networks, which augment their advantages yet further. ${ }^{19}$

\footnotetext{
${ }^{19}$ We thank Wendy Rahn for the investment example, Rucker Johnson for the HIV example, and Eric Hilt for the point about elite education.
} 
6. Explore cases in which network effects may reduce inequality, with attention to the policy implications of such cases. Such cases may enable us to develop programs to reduce inequality by influencing networks or, alternately, by providing functional equivalents to social networks, in order to ameliorate some disadvantages that low-SES persons face in accessing new technologies, new health knowledge, or desirable educational opportunities. 


\section{LITERATURE CITED}

Aberg, Y. 2009. The contagiousness of divorce. Pp. 342-64 in Oxford Handbook of Analytic Sociology, ed. P Hedstrom \& P Bearman. Oxford: Oxford Univ. Press

Aberg, Y, Hedstrom P. 2011. Youth unemployment: a self-reinforcing process. Pp. 201-26 in Analytical Sociology and Social Mechanisms, ed. P Demeulenaere. Cambridge: Cambridge Univ. Press

Abelson H, Miller JD. 1985. A decade of trends in cocaine use in the household population. Pp. 35-50 in Cocaine Use in America: Epidemiologic and Clinical Perspectives, ed. N.J. Kozel \& E.H. Adams. Washington: National Institute on Drug Abuse.

Adamopoulou, E. 2011. Peer effects in young adults' marital decisions. Manuscript, Economics Department, Universidad Carlos III de Madrid

Amuedo-Dorantes C, Mundra K. 2007. Social networks and their impact on the earnings of Mexican Migrants. Demography 44:849-63

Arrow KJ, Borzekowski R. 2004. Limited network connections and the distribution of wages. Finance and Economics Discussion Series 2004-41, Board of Governors of the Federal Reserve System (U.S.). http://econpapers.repec.org/paper/fipfedgfe/200441.htm. Last downloaded July 16, 2011

Arthur WB. 1989. Competing technologies, increasing returns, and lock-in by historical events. Econ. J. 99:116-31

Behrman JR, Kohler H-P, Watkins SC. 2002. Social networks and changes in contraceptive use over time: evidence from a longitudinal study in rural Kenya. Demography 39(4): 713- 
Behrman JR, Kohler H-P, Watkins SC. 2008. Lessons from empirical network analyses on matters of life and death in East Africa. Calif. Center for Pop. Res. On-Line Working Paper Series. http://escholarship.org/uc/item/24h4s7rt Last accessed, Dec. 2, 2011.

Belanger 1996. Le hockey au Québec, bien qu'un jeu: analyse sociologique du hockey dans le projet identitaire des québécois. Loisir et Société 19: 539-57

Berger P, Luckmann T. 1966. The Social Construction of Reality: An Essay in the Sociology of Knowledge. Garden City, N.Y.: Anchor Doubleday.

Bertrand M, Luttmer EFP, Mullainathan S. 2000. Network effects and welfare cultures. Quarterly J. Econ.115 (3): 1019-55

Blau PM. 1977. Inequality and Heterogeneity: A Primitive Theory of Social Structure. New York: Free Press.

Blossfeld H-P. 2009. Educational assortative marriage in comparative perspective. Annu. Rev. Sociol. 35: 513-30

Boorman SA, Levitt PR. 1982. The network matching principle: a model of efficient resource allocation by informal social networks in non-profit and other non-market social structures. Econ. Letters 10(1-2):1-7.

Bortnick SM, Ports MH. 1992. Job search methods and results: tracking the unemployed, 1991. MLR (December): 29-35

Boyd M. 1989. Family and personal networks in international migration: Recent developments and new agendas. Inter. Migration Rev. 23:638-70 Brock WA, Durlauf SN. 2001. Discrete choice with social interactions. Rev. Econ. Studies 68(2): $235-260$ 
Brown K, Laschever R. 2009. When they're sixty-four: peer effects and the timing of retirement. SSRN: http://ssrn.com/abstract=1573757

Brynjolfsson E, Kemerer CF. 1996 Network exsternalities in microcomputer software: An econometric analysis of the spreadsheet market. Mgmt. Sci. 42(12): 1627-47

Bühler C, Fratczak E. 2007 Learning from others and receiving support: the impact of personal networks on fertility intentions in Poland. European Societies 9(3): 359-382 Burke MA, Sass TR. 2008. Classroom peer effects and student achievement. FRB of Boston Working Paper No. 08-5. http://papers.ssrn.com/sol3/papers.cfm?abstract_id=1260882 Last accessed July 22, 2011

Calvo-Armengol A, Jackson MO. 2004. The effects of social networks on employment and inequality. Amer. Econ. R. 94(3): 426-54

Calvó-Armengol A, Patacchini E, Zenou Y. 2009. Peer effects and social networks in education. Rev. Econ. Studies 76: 1239-1267

Card D, Giuliano L. 2011. Peer effects and multiple equilibria in the risky behavior of friends. NBER Working Paper 17088. http://www.nber.org/papers/w17088

Carrell SE, Sacerdote BI, West JE. 2011. From natural variation to optimal policy? The Lucas critique meets peer effects. NBER Working Paper 16865.

http://www.nber.org/papers/w16865.pdf

Case A, Katz L. 1991. The company you keep: the effects of family and neighborhood on disadvantaged youths. NBER Working Paper No. WP3705.

http://www.nber.org/papers/w3705.pdf

Centola D, Macy M. 2007. Complex contagions and the weakness of long ties. Amer. J. Sociol. 113(3): 702-34 
Christakis NA, Fowler JH. 2008. The collective dynamics of smoking in a large social network. N. Engl. J. Med. 358:2249-58

Cohen J. 1977. Sources of peer-group homogeneity. Soc. of Ed. 50: 227-41

Curran SR, Garip F, Chung CY, Tangchonlatip K. 2005. Gendered migrant social capital: evidence from Thailand. Social Forces 84:225-55

DeGiorgi G, Pellizzari M, Redaelli S. 2009. Be as careful of the company you keep as of the books you read: peer effects in education and on the labor market. NBER Working Paper 14948. http://www.nber.org/papers/w14948 Last accessed July 20, 2011

DeSwaan A. 2001. Words of the World. Cambridge, U.K.: Polity Press.

DiMaggio P, Cohen J. 2004. Information inequality and network externalities: a comparative study of the diffusion of television and the Internet." Pp. 227-67 in The Economic Sociology of Capitalism, edited by Victor Nee and Richard Swedberg. Princeton: Princeton Univ. Press DiMaggio P, Garip F. 2011. How network effects can exacerbate intergroup inequality. Am. J. Sociol. 116(6): 1887-1933

DiMaggio P, Hargittai E, Celeste C, Shafer S. 2004. Digital inequality: From unequal access to differentiated use. Pp. 355-400 in Social Inequality, edited by Kathryn Neckerman. New York: Russell Sage Foundation

DiPrete TA, Eirich GM. 2006. Cumulative advantage as a mechanism for inequality: A review of theoretical and empirical developments. Annu. Rev. Sociol. 32: 271-97

Dishion TJ, Tipsord JM. 2011. Peer contagion in child and adolescent social and emotional development. Annu. Rev. Psychol. 62: 189-214

Drewianka S. 2003. Estimating social effects in matching markets: externalities in spousal search. J. of Econ \& Stat. 85: 405-23 
Duflo E, Saez E. 2002. Participation and investment decisions in a retirement plan: the influence of colleagues' choices. J. Public Econ. 85:121-48

Duncan GJ, Boisjoly J, Kremer M, Levy DM, Eccles J. 2005. Peer effects in drug use and sex among college students. J. Abnormal Child Psych. 33(3): 375-85

Durlauf SN, Ioannides YM. 2010. Social interactions. Annu. Rev. Econ. 2:451-78

Edwards H. 1979. Sports within the veil: the triumps, tragedies and challenges of AfroAmerican involvement. Annals of the Amer. Acad. Of Polit. And Soc. Sci. 445(1):116-27 Elliott DS, Menard S. 1996. Delinquent friends and delinquent behavior: temporal and developmental patterns. Pp. 28-67 in Delinquency and Crime: Current Theories, ed. J. D. Hawkins. N.Y.: Cambridge Univ. Press

Ensel WM. 1979. Sex, social ties, and status attainment. Albany, NY: SUNY-Albany Press Epple D, Romano R. 2011. Peer effects in education: A survey of the theory and evidence. Pp. 1053-1163 in Handbook of Social Economics, ed. J Benhabib, A Bisin, MO Jackson. N.Y.: Elsevier

Faris R, Ennet S. 2010 (online). Adolescent aggression, the role of peer group status motives, peer aggression and status characteristics. Social Networks doi:10.1016/ j.socnet.2010.06.003

Fischer CS. 1992. America Calling: A Social History of the Telephone to 1940. Berkeley: Univ. of California Press

Fletcher JM, Tienda M. 2009. High school classmates and college success. Soc. of Educ. $82(4): 287-314$

Freese, J, Lutfey K. 2011. Fundamental causality: challenges of an animating concept for medical sociology. Pp. 67-81 in Handbook of the Sociology of Health, Illness and Healing: A 
Blueprint for the 21st Century, ed. BA Pescosolido, JK Martin, JD McLeod, \& A Rogers. NY: Springer

Fussell E, Massey DS. 2004. The limits to cumulative causation: International migration from Mexican urban areas. Demography 41:151-71

Gabler N. 1989. An Empire of their Own: How the Jews Invented Hollywood. N.Y.: Random House

Gamoran A. 2011. Designing instruction and grouping students to enhance the learning of all: New hope or false promise? Frontiers in Sociology of Education 1(1): 111-26 Garip F. 2008. Social capital and migration: How do similar resources lead to divergent outcomes? Demography 45(3): 591-617

Golub B, Jackson MO. 2011. How homophily affects the speed of learning and best-response dynamics. Ms., Stanford Univ. http://www.stanford.edu/ bgolub/papers/homophily.pdf, last accessed Nov. 2, 2011

Goolsbee A, Klenow PJ. 2002. Evidence on learning and network externalities in the diffusion of home computers. J. of Law \& Econ. 45(2): 317-43

Granovetter M. 1974. Getting a Job. Cambridge: Harvard Univ. Press

Granovetter M. 1978. Threshold models of collective behavior. Am. J. of Soc. 83: 1420-43 Granovetter M. 1994.

Hagan JM. 1998. Social Networks, gender, and immigrant incorporation: Resources and constraints. Amer. Sociol. Rev. 63:55-67

Halliday TJ, Kwak S. 2012. What is a peer? The role of network definitions in estimation of endogenous peer effects. Applied Econ. 44(3): 289-302 
Harding DJ, Gennetian L, Winship C, Sanbonmatsu L, Kling JR. 2010. Unpacking neighborhood influences on education outcomes: setting the stage for future research. NBER Working Paper 1605. http://www.nber.org/papers/w16055 Last accessed July 22, 2011 Haynie D. 2001. Delinquent peers revisited: does network structure matter? Amer. J. Sociol. 106(4): 1013-57

Haynie DL, Osgood DW. 2005. Reconsidering peers and delinquency: How do peers matter? Social Forces 84(2):1109-30

Henry GT, Rickman DK. 2007. Do peers influence children's skill development in preschool? Econ. of Educ. Rev. 26: 100-12

Hensvik L, Asphjell MK, Nilsson JP. 2011. Businesses, buddies and babies: fertility and social interactions at work. Manuscript, Uppsala University.

Hondagneu-Sotelo P. 1994. Regulating the unregulated?: domestic workers' social networks. Soc. Problems 41:50-64

Holzer HJ. 1987. Informal job search and black youth unemployment. Am. Econ. $R$. 77(3):446-52

Hoxby CM. 2000. Peer effects in the classroom: Learning from gender and race variation. NBER Working Paper No. 7867. http://www.nber.org/papers/w7867 Last accessed July 22,2011

Hoxby, C.M., Weingarth, G., 2006. Taking Race Out of the Equation: School Reassignment and the Structure of Peer Effects. Working Paper, Harvard University http://www.aeaweb.org/annual_mtg_papers/2006/0108_1300_0803.pdf Last accessed July 22, 2011 
Hsu G., Hannan MT, Kocak O. 2009. Multiple category memberships in markets: an integrative theory and two empirical tests. Amer. Sociol. Rev. 74(1):150-69.

Ioannides YM, Loury LD. 2004. Job information networks, neighborhood effects, and inequality. J. Econ. Lit:: 42(4): 1056-93

Jencks C, Mayer SE. 1990. The social consequences of growing up in a poor neighborhood. Pp. 111086 in Inner-City Poverty in the United States, ed. JL Lynn, MGH McGreary. Washington, DC: National Academy. Johnson RC, Raphael S. 2009. The effects of male incarceration dynamics on AIDS infection rates among African-American women and men. J. Law \& Econ. 52(2): 251-293.

Kanaiaupuni SM. 2000. Reframing the migration question: an analysis of men, women, and gender in Mexico. Social Forces 78:1311-47

Kandel DB. 1978. Homophily, selection and socialization in adolescent friendships. Amer. J. Sociol. 84(2): 427-36.

Katz M, Shapiro C. 1985. Network externalities, competition and compatibility. Amer. Econ. Rev. 75: 424-40

Kaustia M, Knupfer S. Forthcoming. Peer performance and stock market entry. J. Financial Econ.

Keating NL, O’Malley AJ, Murabito JM, Smith KP, Christakis NA. 2011. Minimal social network effects on cancer screening behavior. Cancer July 1, 2011: 3045-52. Kohler H-P. 2001. Fertility and Social Interaction. N.Y.: Oxford Univ. Press Kohler H-P, Behrman JR, Watkins SC. 2000. Empirical assessments of social networks, fertility and family planning programs: Nonlinearities and their implications. Demographic Research 3(7): 79-126 
Kohler H-P, Behrman JR, Watkins SC. 2001. The density of social networks and fertility decisions: evidence from South Nyanza District, Kenya. Demography 38(1): 43-58

Korenman S, Turner S. 1996. Employment contacts and minority-white wage differences. Industrial Relations 35 (1): 106-22

Kossinets G, Watts DJ. 2009. Origins of homophily in an evolving social network. Amer. J. Sociol. 115(2): 405-50

Kreager DA, Haynie D. 2011. Dangerous liasons? Dating and drinking diffusion in adolescent peer networks. Amer. Sociol. Rev. 76(5): 737-63

Kuziemko I. 2006. Is having babies contagious? Estimating fertility peer effects between siblings. Ms., Harvard Univ. Economics Department. http://www.princeton.edu/ kuziemko/fertility_11_29_06.pdf Last accessed 9/25/11. Laschever R. 2005. The doughboys network: social interactions and labor market outcomes of World War I veterans. Unpublished manuscript, Northwestern University Lavy V, Paserman MD, Schlosser A. 2007. Inside the Black of Box of Ability Peer Effects: Evidence from Variation in High and Low Achievers in the Classroom. NBER Working Paper, http://federation.ens.fr/ydepot/semin/texte0708/LAV2007INS.pdf Last accessed July 22,2011

Liebowitz SJ, Margolis SE. 1994. Network externality: an uncommon tragedy. J. Econ. Perspectives 8(2): 133-50

Lin N. 1999. Social networks and status attainment. Ann. R. Sociol. 25: 467-87

Lin N, Ensel WM, Vaughn JC. 1981. Social resources and strength of ties: Structural factors in occupational status attainment. Amer. Sociol. Rev. 46(4): 292-405 
Liu KY, King M, Bearman PS. 2010. Social influence and the autism epidemic. Amer. J. Sociol. 115(5): 1387-1434

Manski CF. 1993. Identification of endogenous social effects: the reflection problem. Rev. of Econ. Studies 60(3): 531-42

Marmaros D, Sacerdote B. 2002. Peer and social networks in job search. Euro. Econ. Rev. 46(4-5): 870-79

Marsden P, Gorman EH. 2001. Social networks, job changes, and recruitment. Pp. 467-502 in Sourcebook of Labor Markets: Evolving Structure and Processes, ed. I Berg \& AL Kalleberg. NY: Kluwer Academic/Plenum Publishers Marwell, G, Oliver P. 1993. The Critical Mass in Collective Action: A Micro-Social Theory. N.Y.: Cambridge Univ. Press.

Massey DS. 1986. The social organization of Mexican migration to the United States. Annals of the Amer. Acad.of Polit. and Soc. Sci. 487:102-13

Massey DS, Espinosa KE. 1997. What's driving Mexico-U.S. migration? A theoretical, empirical, and policy analysis. Amer. J. Soc. 102:939-99

McDermott, R, Fowler JH, Christakis NA. 2009. Breaking up is hard to do, unless everyone else is doing it too: social network effects on divorce in a longitudinal sample followed for 32 years. http://papers.ssrn.com/sol3/papers.cfm?abstract_id=1490708 McFarland D, Pals H. 2005. Motives and contexts of identity change: A case for network effects. Soc. Psych. Q. 68(4): 289-315 McPherson JM, Smith-Lovin L, Cook JM. 2001. Birds of a feather: homophily in social networks. Annu. Rev. Sociol. 27: 415-44 
Mercken L, Snijders TAB, Steglich C, Vartiainen E, DeVries H. 2009. Dynamics of adolescent friendship networks and smoking behavior. Social Networks 32(1): 720-81

Merton RK. 1968. The Matthew effect in science. Science 159 (3810): 56-63

Montgomery JD. 1991. Social networks and labor-market outcomes: toward an economic analysis. Am. Econ. R. 81 (5): 1408-18

Mouw T. 2002. Social capital and finding a job: do contacts matter? Amer. Sociol. Rev. 68(6): 868-98

O’Malley AJ \& Christakis NA. 2009. Longitudinal analysis of large social networks: estimating the effect of health traits on changes in friendship ties. Stats. In Med. 30: 950-64. Pampel FC, Krueger PM, Denney JT. Socioeconomic disparities in health behaviors. Annu. Rev. Sociol. 36:349-70

Patacchini E, Zenou Y. 2011. Juvenile delinquency and conformism. J. Law, Econ. \& Org. Advance access, last accessed, Nov. 10, 2011. http://jleo.oxfordjournals.org/content/early/2009/12/09/jleo.ewp038.full.pdf Pescosolido BA. 1992. Beyond rational choice: the social dynamics of how people seek help. Amer. J. Sociol. 97(4): 1096-1138

Prentice DA, Miller DT. 1993. Pluralistic ignorance and alcohol use on campus: some consequences of misperceiving the social norm. J. Personality \& Social Psych. 64(2):243-56. Rivera M, Soderstrom SB, Uzzi B. 2010. Dynamics of dyads in social networks: assortative, relational, and proximity mechanisms. Annu. Rev. Sociol. 36:91-115.

Rogers EM. 1995. Diffusion of Innovations. $4^{\text {th }}$ ed. New York: The Free Press Rosenfeld MJ. 2008. Racial, educational and religious endogamy in the U.S.: a comparative historical perspective. Soc. Forces 87(1):1-31 
Rossman G. 2012. Climbing the Charts: What Radio Airplay Tells Us about the Diffusion of Innovation. Princeton: Princeton Univ. Press

Rossman G, Chiu MM, Mol JM. 2008. Modeling diffusion of multiple innovations via multilevel diffusion curves: payola in pop music radio. Sociol. Methodology38 (1): 201-30 Sacerdote B. 2011. Peer effects in education: How might they work, how big are they and how much do we know thus far? Handbook of the Economics of Education 3: 249-77 Sampson RJ, Morenoff JD, Gannon-Rowley T. 2002. Assessing 'neighborhood effects': social processes and new directions in research. Annu. Rev. Sociol. 28: 443-478

Schwartz CR. 2010. Earnings inequality and the changing association between spouses' earnings. Amer. J. Soc. 115:1524-57

Schwartz CR, Mare RD. 2005. Trends in educational assortative marriage from 1940 to 2003. Demography 42:621-46

Shalizi CR, Thomas AC. 2011. Homophily and contagion are generically confounded in observational social network studies. Sociol. Methods and Res. 40(2): 211-39

Shue K. 2011. Executive networks and firm policies: evidence from the random assignment of MBA peers. http://www.people.fas.harvard.edu/ shue/papers/jmp_kellyshue.pdf. Downloaded July 17, 2011

Shy 0. 2001. The Economics of Network Industries. New York: Cambridge Univ. Press Smith KP, Christakis NS. 2008. Social networks and health. Annu. Rev. Sociol. 34:405-29 Smith SS. 2005. 'Don't put my name on it': social capital activation and job-finding assistance among the black urban poor. Amer. J. Sociol. 111 (1): 1-57

Strang D, Meyer JW. 1993. Institutional conditions for diffusion. Theory \& Society 21(4): 487-511 
Strang D, Soule SA. 1998. Diffusion in organizations and social movements: From hybrid corn to poison pills. Annu. Rev. Sociol. 24: 265-90

Van den Bulte C, Stremersch S. 2004. Social contagion and income heterogeneity in new product diffusion: a meta-analytic test. Marketing Sci. 23(4): 530-44

VanderWeele TJ. 2011. Sensitivity analysis for contagion effects in social networks. Sociol. Mehods \& Res. 40(2):240-55

Varian HR, Farrell J. 2004. The Economics of Information Technology: An Introduction. New York: Cambridge Univ. Press

Watkins SC, Warriner I. 2003. How do we know we need to control for selectivity? Demographic Research, Special Collection 1: 109-42. http://www.demographicresearch.org/special/1/4/ Last accessed Nov. 12, 2011.

Watts DJ. 1999. Networks, dynamics and the small-world phenomenon. Amer. J. Sociol. 105(2): 493-527.

Young, HP. 2009. Innovation diffusion in heterogeneous populations: Contagion, social influence, and social learning. Amer. Econ. Rev. 99(5): 1899-1924. 
Table 1: Types of Mechanisms by Which Networks Affect Adoption*

\begin{tabular}{|c|c|c|c|c|c|}
\hline Type of Mechanism & Variant & Network Effect & Characteristics & Stylized Example & Measure \\
\hline Pure Externality & & & Complex, repeated (all types) & & \\
\hline \multirow{4}{*}{$\begin{array}{l}\text { Fingerprint: effect is a } \\
\text { function of full network }\end{array}$} & linear benefit & each new adopter adds equal value & ibid. & food co-op & $N$ of adopters in network \\
\hline & declining benefit & $\begin{array}{l}\text { past some point each adopter adds } \\
\text { less value }\end{array}$ & ibid. & e-mail; social identities & $\log N$ of adopters in network \\
\hline & rising benefit & $\begin{array}{l}\text { value derived from interactions } \\
\text { among peers, as well as with peers }\end{array}$ & ibid. & online user community & $\begin{array}{l}\text { exponential function of } \mathrm{N} \text { adopters } \\
\text { in network }\end{array}$ \\
\hline & $\begin{array}{l}\text { competing-platforms (hybrid form with } \\
\text { normative influence) }\end{array}$ & $\begin{array}{l}\text { ego must choose between } \\
\text { al ternatives }\end{array}$ & ibid. & Excel v. Lotus (1980s) & $\begin{array}{l}\text { percentage of network peers who } \\
\text { have adopted each al ternative }\end{array}$ \\
\hline \multicolumn{6}{|l|}{ Social learning } \\
\hline \multirow[t]{4}{*}{$\begin{array}{l}\text { Fingerprint: effects with } \\
\text { thresholds }\end{array}$} & awareness & $\begin{array}{l}\text { value obvious, awareness suffices } \\
\text { for adoption }\end{array}$ & simple, one-time & $50 \%$-off sale at supermarket & $\begin{array}{l}p \text { of observing prior adoption by at } \\
\text { least one network peer }\end{array}$ \\
\hline & peer testimony & $\begin{array}{l}\text { expected value based on thick } \\
\text { information from peers }\end{array}$ & complex, one-time & finding a good doctor; opening an IRA & threshold where $N>1$ \\
\hline & adoption assistance & peer input needed for effective adoption & complex, one-time & having a child & ibid. \\
\hline & $\begin{array}{l}\text { ongoing support (hybrid form with pure } \\
\text { externalities) }\end{array}$ & $\begin{array}{l}\text { continued peer input required for } \\
\text { continued effectiveness }\end{array}$ & complex, repeated & migrating for work & $\log N$ of adopters in network \\
\hline Normative In fluence & & & complex, repeated & & \\
\hline \multirow{2}{*}{$\begin{array}{l}\text { Fingerprint: effect } \\
\text { influenced } \\
\text { by density of ties among } \\
\text { contacts }\end{array}$} & Critical mass & $\begin{array}{l}\text { sustained positive \& negative sanctioning; } \\
\text { categ orical legitimation through modeling }\end{array}$ & ibid. & smoking cessation, dieting & $\begin{array}{l}\text { percentage of prior adopters weighted by } \\
\text { density of ties among those adopters }\end{array}$ \\
\hline & Competing norms & contending sanctioning regimes & ibid. & use of standard vs. coll oquial language & $\begin{array}{l}\text { difference between percentage of ties } \\
\text { observing each norm weighted by } \\
\text { density of ties among those peers }\end{array}$ \\
\hline
\end{tabular}




\section{Terms/Definitions list:}

Complex contagion. Transmission of behavior requiring $>1$ contact between a prior adopter and an actor at risk to adopt.

Correlated status parameters. Degree to which measures of social status or social advantage overlap, with high correlations limiting intergroup contact and mobility.

Ego/alter. Ego is the focal node in a network. Alters are the nodes to which ego is connected directly.

Diffusion. The process by which a practice spreads throughout (is adopted by) members of a population.

Homophily. The tendency of actors in a network to form ties to alters who are similar to themselves.

Network effect. Effect on ego of alters' behavior.

Network externalities (global). Benefits to an adopter deriving directly from the total number of adopters.

Network exernalities (local). Benefits to an adopter deriving directly from the number of its network alters who have adopted.

Network interaction effects. The conditioning of the strength of a network effect on some characteristic on which network members vary.

Normative influence. Network effects on ego's adoption of a practice due to positive or negative sanctions.

Peer effects. Effects on actor of the behavior of actors in its vicinity (e.g., classroom, organization, or neighborhood).

Reservation price. An adoption threshold: The price (in money, time, or effort) an actor will pay to adopt a new practice. 
Selection into networks (also "network endogeneity"). Correlations among the behaviors of network members due to those members seeking out alters with those behaviors.

Social learning. Network effects on ego's adoption of a practice due to the transfer of information or assistance.

Social network. A set of actors (nodes) connected by a set of relations (ties or edges)

Simple contagion. Transmission of a behavior requiring only one contact between a prior adopter and an actor at risk to adopt.

Small worlds. Large networks characterized by densely connected subgraphs, sparsely connected to one another by bridging ties.

\section{Acronyms: NONE}

\section{Summary Points list:}

1. Social network effects on the adoption of practices that help people get ahead (or on risky behaviors that may impede mobility) may under certain conditions increase intergroup inequality.

2. They are likely to do so when high-SES individuals are more likely, based on individual resources, to adopt beneficial practices (or less likely to adopt harmful practices) and when networks are characterized by homophily with respect to SES.

3. Despite methodological challenges, much research in both sociology and economics, demonstrates robust network effects on many behaviors related to schooling, labor-market participation, health-related behaviors, economic choices, demographic transitions, substance abuse and delinquent behavior.

4. Some research suggests that the strength of network effects may be greater for actors with initial advantages, thus reinforcing the tendency of network effects to exacerbate inequality.

5. A very small amount of research demonstrates cases in which network effects are associated with increasing inequality in some practice between actors in different villages, cities, or organizations. 
6. Under some conditions, network effects may ameliorate inequality.

Future Issues list [AU note: This duplicates the last section of the ms.]:

1. Specify mechanisms and test alternative specifications.

2. Employ computational models to understand better the implications for social inequality of different network-effect mechanisms.

3. Conduct research on the impact of network effects on inequality with appropriate data (with repeated observations of network ties, adoption of beneficial practices, and change in intergroup inequality).

4. Differentiate among types of relationship.

5. Study ways in which institutions condition the impact of network effects on inequality.

6. Explore cases in which network effects may reduce inequality. 